\title{
Luminescence complementation technology for the identification of MYC:TRRAP inhibitors
}

\author{
Edmond J. Feris ${ }^{1,2}$, John W. Hinds ${ }^{1,2}$ and Michael D. Cole $e^{1,2}$ \\ ${ }^{1}$ Department of Molecular and Systems Biology, Geisel School of Medicine at Dartmouth College, Hanover, NH 03755, USA \\ ${ }^{2}$ Norris Cotton Cancer Center, Dartmouth-Hitchcock Medical Center, Lebanon, NH 03756, USA \\ Correspondence to: Michael D. Cole, email: mcole@dartmouth.edu \\ Keywords: cancer; drug discovery; targeted therapy; oncogene; transcription factor \\ Received: May 15, $2021 \quad$ Accepted: September 04, $2021 \quad$ Published: October 12, 2021
}

Copyright: (c) 2021 Feris et al. This is an open access article distributed under the terms of the Creative Commons Attribution License (CC BY 3.0), which permits unrestricted use, distribution, and reproduction in any medium, provided the original author and source are credited.

\section{ABSTRACT}

Mechanism-based targeted therapies have exhibited remarkable success in treating otherwise untreatable or unresectable cancers. Novel targeted therapies that correct dysregulated transcriptional programs in cancer are an unmet medical need. The transcription factor MYC is the most frequently amplified gene in human cancer and is overexpressed because of mutations in an array of oncogenic signaling pathways. The fact that many cancer cells cannot survive without MYC - a phenomenon termed "MYC addiction" - provides a compelling case for the development of MYC-specific targeted therapies. We propose a new strategy to inhibit MYC function by disrupting its essential interaction with TRRAP using small molecules. To achieve our goal, we developed a platform using luminescence complementation for identifying small molecules as inhibitors of the MYC:TRRAP interaction. Here we present validation of this assay by measuring the disruption of TRRAP binding caused by substitutions to the invariant and essential MYC homology 2 region of MYC.

\section{INTRODUCTION}

Recent years have been marked by a focused recalibration of drug discovery engines in the pharmaceutical and biotechnology worlds. Rising costs of research and development hinder the pursuit of targets without the greatest substantial value. Historical failure coupled with low probability of success and lack of novel approaches have focused efforts into the pursue of new therapeutic strategies. However, mechanism-based targeted therapies have exhibited remarkable success in treating otherwise untreatable or unresectable cancers [1]. Amongst these, the most successful are chemical or biological entities that specifically target cancerous cellular states and have minimal effects on normal cellular programs.

Novel targeted therapies that correct dysregulated transcriptional programs in cancer are an unmet medical need [2]. The transcription factor MYC is the most frequently amplified gene in human cancer and is overexpressed because of mutations in an array of oncogenic signaling pathways $[3,4]$. The fact that many cancer cells cannot survive without MYC - a phenomenon termed "MYC addiction" - provides a compelling case for the development of MYC-specific targeted therapies $[2,5-8]$. Therefore, MYC has been recognized as the "most wanted' target in cancer for decades, but most efforts have met with inescapable off-target toxicity [9-11]. Despite attempts at inhibiting MYC expression, its direct interaction with DNA and its obligate partner MAX, or any indirect MYC effectors, no clinically useful drug has emerged in nearly 20 years due to poor accessibility and specificity $[9,11,12]$.

Since MYC has no inherent enzymatic activity, it has been inaccurately described as an "undruggable" target [9-11]. However, it does have a functional DNAbinding domain and a transactivation domain (TAD). The DNA-binding domain requires a protein-protein interaction (PPI) with its obligate partner MAX. Several labs have attempted to find small molecules that inhibit 
MYC:MAX with limited success [9-11]. It is informative to point out the timeline of MYC:MAX inhibitor research. The first MYC:MAX inhibitor was reported in 2002, and it functioned at 50-100 $\mu \mathrm{M}$ [13]. Improved analogs of this inhibitor $(\sim 25 \mu \mathrm{M})$ were reported in 2007 [14] and other inhibitors have been reported more recently [12, 15-18]. However, the specificity of these inhibitors for MYC:MAX is often unclear.

We propose a new strategy to inhibit MYC function by disrupting the MYC:TRRAP interaction using small molecules. TRRAP is one of the best characterized MYC cofactors and is an essential component of various histone acetyltransferase (HAT) complexes [5, 19-23]. The identification of TRRAP as an essential MYC cofactor established a link to HAT complexes containing GCN5 and TIP60 and provided an important mechanistic insight into MYC function [10, 19, 21-23]. The MYC:TRRAP interaction occurs at a precise motif in the TAD of MYC known as the MYC Homology Box 2 (MB2) [5, 21]. The importance of MB2 in MYC-driven tumorigenesis is well established in cellular assays and animal models [24, 25], presumably because it is necessary for the MYC:TRRAP interaction. Therefore, the TAD of $\mathrm{MYC}, \mathrm{MB} 2$, and MYC:TRRAP are required for MYC-driven transactivation and cancer promotion. Furthermore, MB2 is unique and nearly invariant in evolution $[5,19]$, suggesting that it is an ideal site for inhibiting MYC function.

Here we present a robust and high-throughputamenable platform that can be used to identify inhibitors of the MYC:TRRAP interaction. Using luminescence complementation and the minimal MYC and TRRAP interacting domains, we developed a PPI assay that results in an active luciferase enzyme when MYC:TRRAP complexes form. We used the NanoLuc ${ }^{\circledR}$ Binary Technology $\left(\mathrm{NanoBiT}^{\circledR}\right)$, a split version of the NanoLuc ${ }^{\circledR}$ luciferase (a $19.1 \mathrm{kDa}$ protein that produces an ATPindependent glow-type luminescence with half-life $>2$ h; Promega Corporation) intended for measurement of PPIs in live cells [26]. Unlike co-IPs and other binding assays, the NanoBiT ${ }^{\circledR}$ system enables quantifiable measurements without cell lysis. With high sensitivity and broad dynamic range, bioluminescent methods have proven useful for many applications, including binding assays and drug discovery. We validated our assay by identifying substitution mutations in MB2 that result in loss of TRRAP binding and correlate with loss of MYCdriven cellular transformation.

\section{RESULTS}

\section{TRRAP 2033-2283 is the minimal MYC-binding domain}

We previously showed that MYC 1-190 is sufficient for a stable MYC:TRRAP interaction [5], and we wanted to identify the minimal domain of TRRAP that is sufficient for complex formation. TRRAP 1997-2401 binds to MYC and TRRAP 1997-2088 is required but not sufficient to sustain the MYC:TRRAP interaction in co-IP assays [5]. Further deletion studies show that a minimal domain of TRRAP (2033-2283) is sufficient for protein complex formation in co-IP experiments (Figure 1A). To validate this mapping, co-IP experiments were performed to test if TRRAP 2033-2283 is essential in the native MYC:TRRAP complex. A competition experiment between the TRRAP 2033-2283 domain and native MYC:TRRAP complexes shows that overexpression of the critical TRRAP domain inhibited formation of native MYC:TRRAP complexes (Figure 1B). This effect was attenuated when the core internal binding region of TRRAP (2033-2088) was not present (Figure 1B, lane 3).

\section{MYC:TRRAP luminescence complementation platform is MB2-dependent}

Defining the minimal domains that form the MYC:TRRAP complex allowed us to develop an assay for PPI using the NanoBiT ${ }^{\circledR}$ PPI system, which fuses the Large Binary Technology (LgBiT) and Small Binary Technology (SmBiT) subunits to different interacting proteins. Briefly, residues 2033-2283 of TRRAP and 1-190 of MYC were respectively cloned into CMV-driven vectors containing the $\mathrm{LgBiT}(18 \mathrm{kDa})$ and $\mathrm{SmBiT}$ (11aa) subunits to monitor the MYC:TRRAP PPI (Table 1). Upon protein dimerization of MYC:TRRAP, the NanoBiT ${ }^{\circledR}$ subunits complement and form a highly active luciferase enzyme (Figure 2A).

Next, we measured MYC:TRRAP complex formation using luminescence complementation. The minimal interacting domains described above gave a robust luminescence, whereas deletion of MYC Homology Box 2 (MB2, amino acids 128-144) reduced luminescence by $90 \%$ both in cells and in cellular extracts (Figure 2B compare bars 1 and 2). Thus, this luciferase assay appears to recapitulate the in vivo MYC:TRRAP interaction [5, 21]. As a control, we measured the expression of both MYC and MYC $\triangle \mathrm{MB} 2$ using the NanoBiT system. The $\mathrm{LgBiT}$ and SmBiT subunits are able to associate independently with a $\mathrm{Kd}$ of $190 \mu \mathrm{M}$ [27]. Therefore the LgBiT subunit alone was co-transfected in excess to allow independent association with the SmBiT subunit in both MYC and MYC $\triangle \mathrm{MB} 2$. This provides a measurement that shows equal expression for both MYC and MYC $\triangle \mathrm{MB} 2$ constructs (Figure 2B lanes 4 and 5).

One additional LgBiT-TRRAP construct was tested for luminescence. To confirm the importance of the TRRAP 2033-2088 domain, luminescence was measured with TRRAP 2033-2283 compared to a similar construct lacking the MYC binding region, TRRAP 2088-2283 (Supplementary Figure 1). Like MB2, the absence of TRRAP 2033-2088 diminishes binding, consistent with co-IP experiments [5]. 


\section{MB2 substitutions affect TRRAP binding and cellular transformation}

To validate luminescence complementation measurements further, we tested if this assay could provide reliable measurements of MYC:TRRAP binding perturbation caused by a single residue substitution mutation (W135E). MYC W135 is within the core of MB2, and previous reports showed that W135 is essential for MYC-driven cellular transformation and transactivation [24, 28, 29]. Nevertheless, the involvement of W135 in TRRAP binding has been unclear. Using the

A

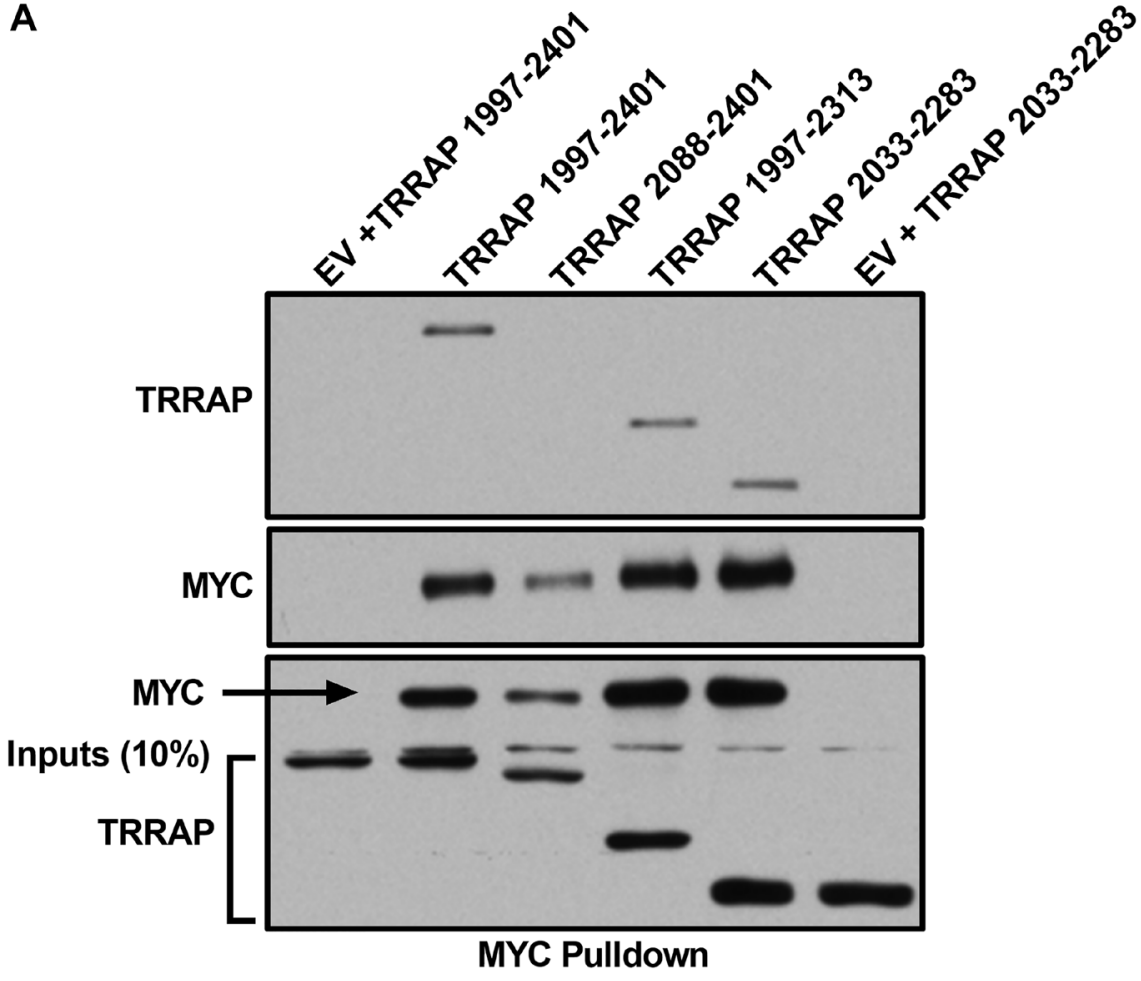

B

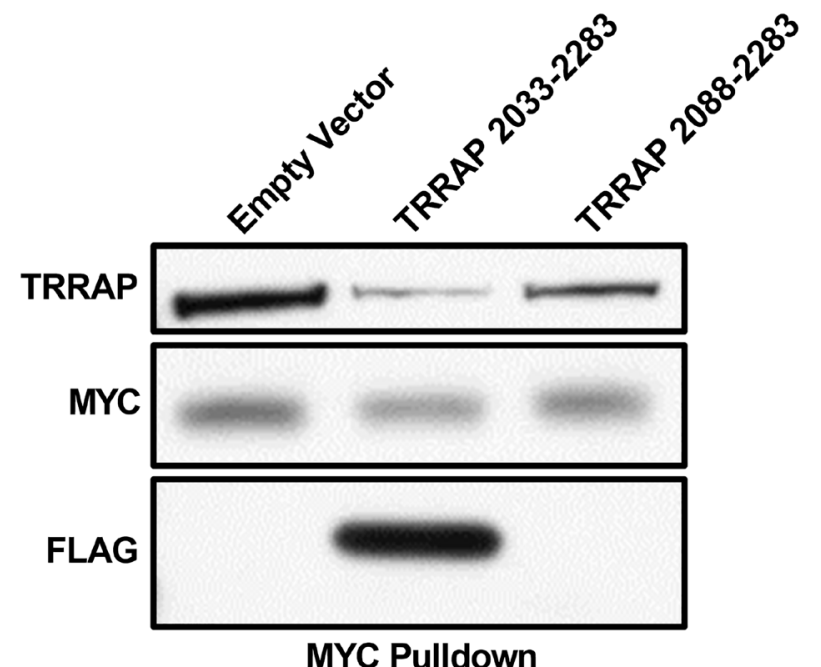

Figure 1: TRRAP 2033-2283 is the minimal MYC-binding domain. (A) Western blot analysis of a co-immunoprecipitation experiment where the indicated regions of TRRAP were cloned into a CMV-FLAG expression vector and transfected into HEK293T cells. Proteins were co-expressed with PYO-tagged full-length MYC and then MYC was IP'd with anti-PYO beads. Co-IP was assessed by western blot with anti-FLAG. The most critical binding domain is within residues 2033-2088, consistent with previous results [5], and the minimal domain TRRAP 2033-2283 is established. (B) Western blot analysis of a co-immunoprecipitation experiment where the indicated regions of TRRAP were cloned into a CMV-FLAG expression vector and transfected into HEK293T cells. Endogenous MYC was IP'd with C-33 beads (Santa Cruz Biotechnology). The TRRAP and FLAG blots show TRRAP 2033-2283 can compete off the endogenous native MYC:TRRAP complex in cells, but the same domain of TRRAP lacking the critical region 2033-2088 does not show the same level of competition. 
Table 1: Key resources table

\begin{tabular}{|c|c|c|}
\hline Reagent or Resource & Source & Identifier \\
\hline \multicolumn{3}{|l|}{ Antibodies } \\
\hline Rabbit polyclonal anti-MYC & Santa Cruz Biotechnology & sc-764 \\
\hline Rabbit polyclonal anti-FLAG & Millipore Sigma & F7425 \\
\hline $\begin{array}{l}\text { Mouse monoclonal anti-Glu-Glu Epitope Tag Affinity } \\
\text { Matrix }\end{array}$ & BioLegend & AFC-115P-1000 \\
\hline Mouse monoclonal anti-MYC agarose conjugate & Santa Cruz Biotechnology & sc-42 AC \\
\hline Rabbit polyclonal anti-MYC & Cell Signaling Technology & 9402 \\
\hline Rabbit polyclonal anti-TRRAP & Bethyl Laboratories & A301-132A \\
\hline Mouse monoclonal anti-MAX & Santa Cruz Biotechnology & sc-8011 \\
\hline Mouse monoclonal anti-V5 & Invitrogen & 46-0705 \\
\hline Mouse monoclonal anti-Vinculin & Santa Cruz Biotechnology & sc-73614 \\
\hline \multicolumn{3}{|l|}{ Critical Commercial Assays } \\
\hline NanoBiT $^{\circledR}$ PPI System & Promega & N2014 \\
\hline Nano-Glo ${ }^{\circledR}$ Live Cell Assay System & Promega & N2012 \\
\hline ExpiFectamine $^{\mathrm{TM}} 293$ Transfection Kit & Gibco $^{\mathrm{TM}}$ & A14524 \\
\hline LipoD293 $^{\mathrm{TM}}$ & SignaGen & SL100668 \\
\hline \multicolumn{3}{|l|}{ Experimental Models: Cell Lines } \\
\hline HEK293T & ATCC & CRL-3216, RRID:CVCL_0063 \\
\hline Expi293F & Gibco $^{\mathrm{TM}}$ & A14527, RRID:CVCL_D615 \\
\hline MCF-10A & ATCC & CRL-10317, RRID:CVCL_0598 \\
\hline \multicolumn{3}{|l|}{ Recombinant DNA } \\
\hline Plasmid: C $\beta$ P MYC 1-190 & This paper & N/A \\
\hline Plasmid: C $\beta F$ TRRAP 2033-2283 & This paper & N/A \\
\hline Plasmid: C $\beta 2$ N MYC 1-190 & This paper & $\mathrm{N} / \mathrm{A}$ \\
\hline Plasmid: C $\beta 1 C$ TRRAP 2033-2283 & This paper & $\mathrm{N} / \mathrm{A}$ \\
\hline Plasmid: pCDH V5-MYC 1-439 & This paper & N/A \\
\hline \multicolumn{3}{|l|}{ Software and Algorithms } \\
\hline Prism & GraphPad & N/A \\
\hline Image Studio ${ }^{\mathrm{TM}}$ & LI-COR & N/A \\
\hline
\end{tabular}

luminescence complementation platform, we found that a W135E substitution reduced MYC:TRRAP binding in cells to $\sim 25 \%$ of WT (Figure $3 \mathrm{~A}$ ). We also validated this measurement using the native MYC:TRRAP complex in a co-IP experiment (Figure 3B).

To further explore the MB2-dependence of MYC:TRRAP binding, a series of point mutations was created in SmBiT-MYC 1-190, and any changes in TRRAP 2033-2283 binding were measured via luminescence complementation. Residues with high evolutionary conservation (M134, W135, S136, and F138) were each substituted with alanine residues [30]. We also included the most common MYC mutation in cancer, T58I/A/P/N [31-38]. Unsurprisingly this cancer-associated mutation appeared to increase TRRAP binding. However, after normalization for MYC expression there was no apparent effect on TRRAP binding. The T58I mutation has been reported as a MYC protein stabilizing mutation. The higher MYC expression results in more MYC:TRRAP complexes but there is no increased binding to TRRAP at comparable MYC expression levels. Therefore, the expression level for each construct had to be determined with the previously described luminescence-based assay (Supplementary Figure 2) and used to normalize TRRAP binding measurements (Figure 4A). Alanine substitutions at the most conserved MB2 residues (M134A, W135A, S136A, F138A) confirmed their importance in the MYC:TRRAP interaction, with decreased binding to $\sim 20$ $40 \%$ of WT (Figure 4A). Since both W135A and W135E are defective, it is likely that the bulkier hydrophobicity of the tryptophan is critical. M134A also caused a significant decrease in luminescence complementation, though not 


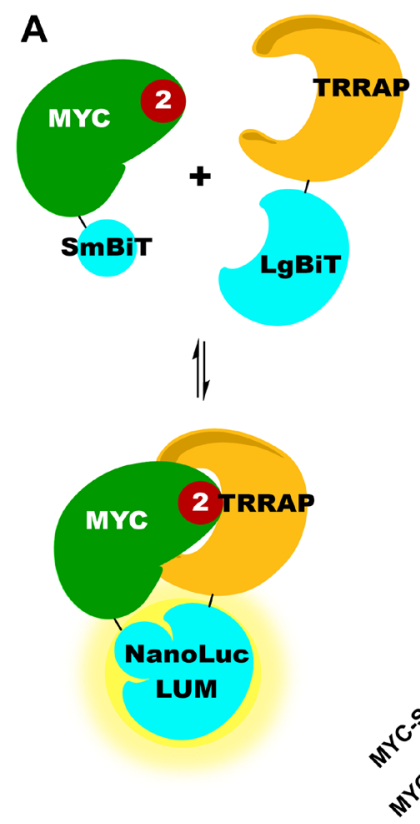

\section{B}
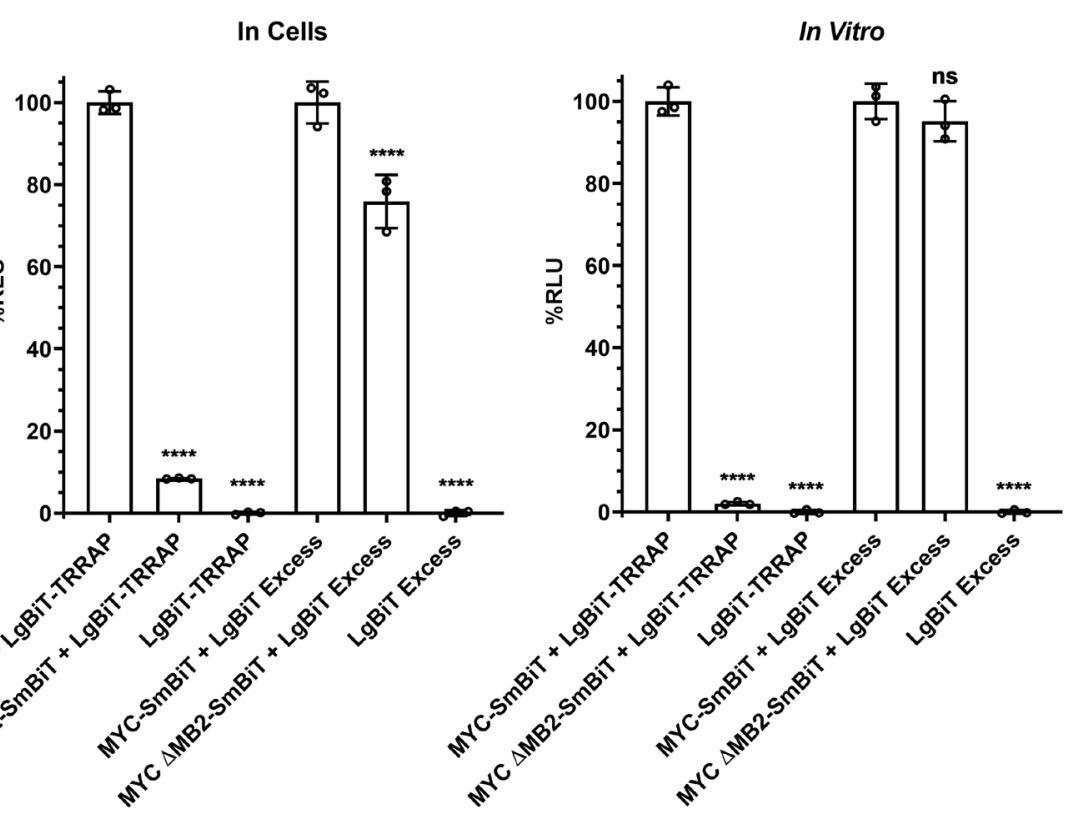

Figure 2: MYC:TRRAP luminescence complementation platform is MB2-dependent. (A) Schematic representation of MYC 1-190 and TRRAP 2033-2283 fused to each subunit of the NanoLuc ${ }^{\circledR}$ Binary Technology (NanoBiT) system. (B) Luminescence measurements of cells transfected with TRRAP 2033-2283-LgBiT and SmBiT-MYC 1-190 with and without MB2 and alone. The LgBiT subunit was co-transfected in excess with SmBiT-MYC 1-190 (+/- MB2) and alone. The panel on the left shows measurements carried out in cells while the right panel shows measurements in cellular extracts. A 10-fold decrease is observed with the deletion of MB2. MYC binding to TRRAP is MB2 dependent, validating in vivo immunoprecipitation experiments with native proteins [5,21]. An unpaired Student's $t$-test was performed to determine standard deviation and statistical significance. $P$-value $\leq 0.05$ was considered statistically significant. Error bars represent SD and ns: $p>0.05,{ }^{*}: p \leq 0.05,{ }^{* *}: p \leq 0.01,{ }^{* * *}: p \leq 0.001,{ }^{* * * *}: p \leq 0.0001$.
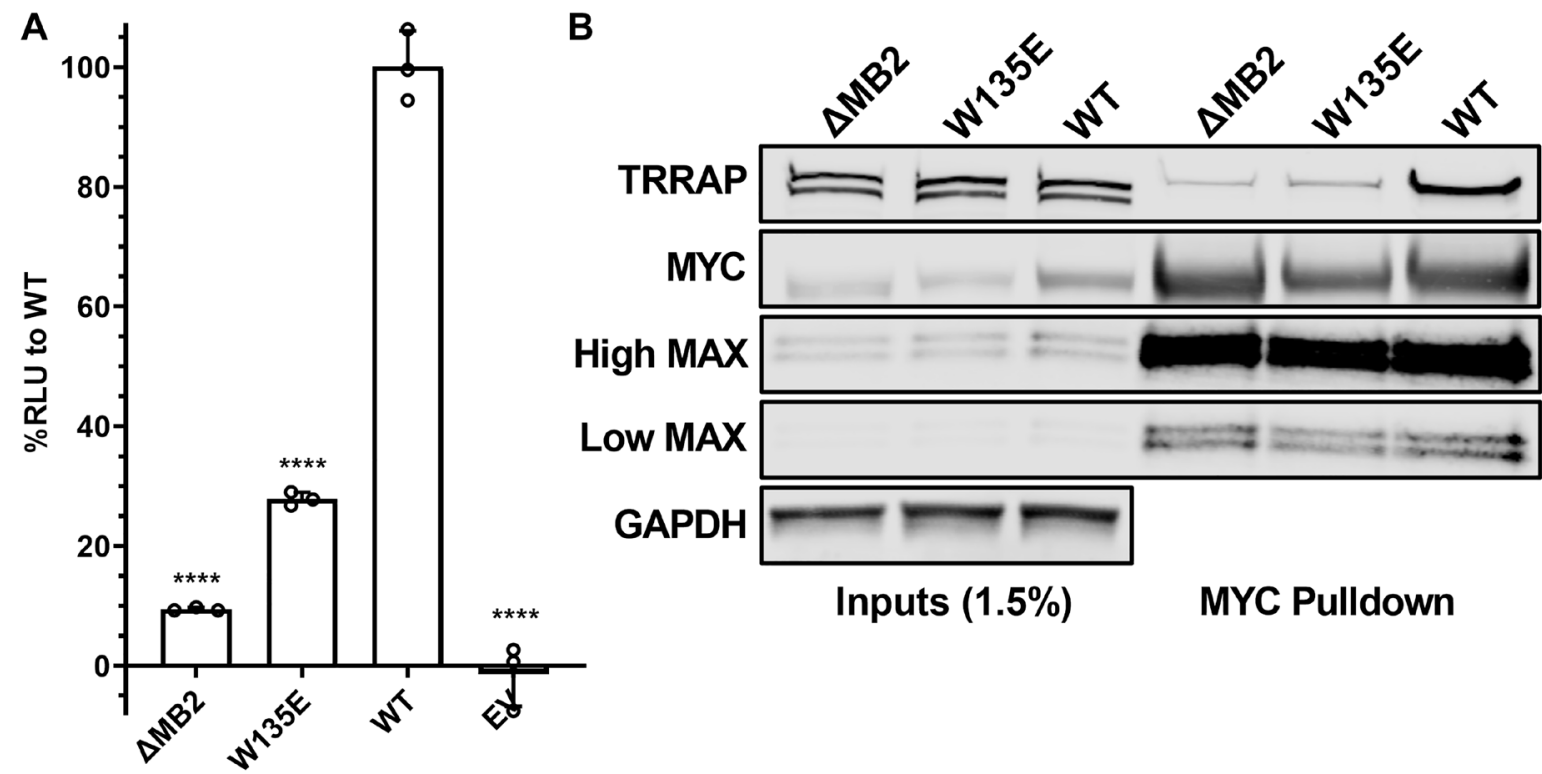

Inputs (1.5\%)

MYC Pulldown

Figure 3: W135 is essential for MYC:TRRAP. (A) Luminescence measurements of cells transfected with TRRAP 2033-2283-LgBiT and empty vector, SmBiT-MYC 1-190 (+/- MB2), and with a W135E substitution. These results indicate the importance of W135 for the MYC:TRRAP interaction. An unpaired Student's $t$-test was performed to determine standard deviation and statistical significance. $P$-value $\leq 0.05$ was considered statistically significant. Error bars represent SD and ns: $p>0.05,{ }^{*} p \leq 0.05,{ }^{* *} p \leq 0.01,{ }^{* * *} p \leq 0.001,{ }^{* * * *} p$ $\leq 0.0001$. (B) Western blot analysis of a coimmunoprecipitation experiment where the native TRRAP and MYC proteins or the indicated MYC mutants were co-transfected into Expi293F cells. PYO-tagged full-length MYC was co-expressed with FLAG-tagged full-length TRRAP and then MYC was IP'd with anti-PYO beads. High/low MAX refers to exposure time. These results validate the MYC:TRRAP NanoBiT platform and indicate that it can provide quantifiable measurements that recapitulate the binding interaction of the native MYC:TRRAP complex. 
as much as W135A/E. Since F138A showed the same decrease in luminescence as $\mathrm{W} 135 \mathrm{~A} / \mathrm{E}$, it suggests that F138 may have an important participation in the MYC:TRRAP interaction. In contrast, the most common and recurrent MYC mutation in cancer, T58I, showed no change in TRRAP binding, despite a significant increase in expression (Supplementary Figure 2).

To test if TRRAP binding measurements with MB2 substitution mutants affect MYC activity, we tested if these mutations have a correlation with disruption of MYC-driven cellular transformation as measured by anchorage independent growth (Figure 4B). MCF10A cells overexpressing MYC have been proposed to be a cellular model for triple negative breast cancer $[25,39,40]$. A Growth in Low Attachment (GILA) assay was developed as a quantifiable measure of anchorageindependent growth which is a marker of cellular transformation [41]. GILA measurements were performed with MCF-10A cells engineered with ectopic expression of full-length WT MYC or with the indicated substitutions
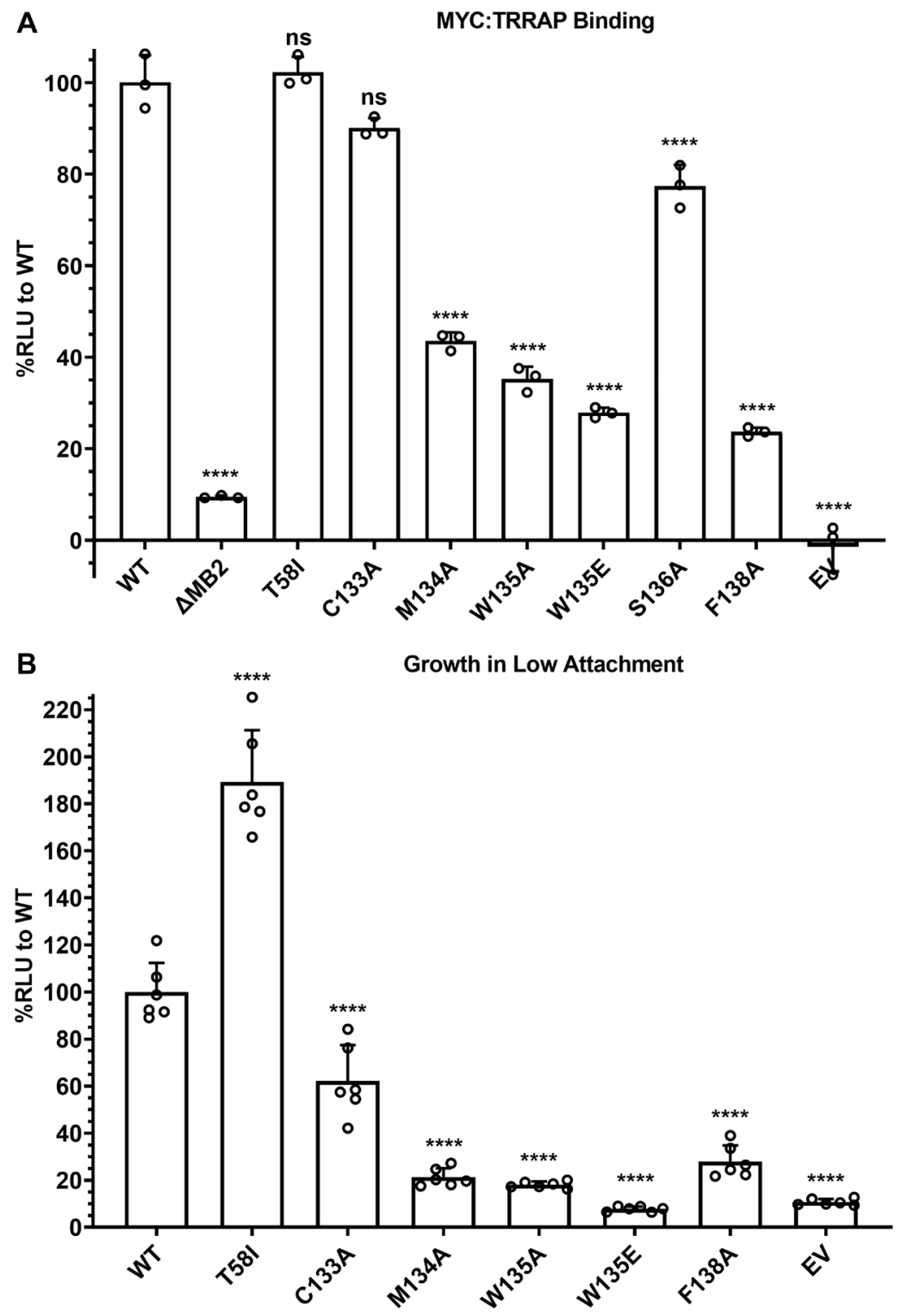

Figure 4: MB2 substitutions affect TRRAP binding and cellular transformation. (A) Luminescence measurements of cells transfected with TRRAP 2033-2283-LgBiT and the indicated SmBiT-MYC 1-190 or mutants. These results show the effects of substitution mutations in MB2 on TRRAP binding. An unpaired Student's $t$-test was performed to determine standard deviation and statistical significance. $P$-value $\leq 0.05$ was considered statistically significant. Error bars represent SD and ns: $p>0.05,{ }^{*} p \leq 0.05,{ }^{* *} p \leq 0.01,{ }^{* * *} p$ $\leq 0.001,{ }^{* * * *} p \leq 0.0001$. (B) Luminescence measurements indicating proliferation of MCF-10A cells evaluated for their ability to grow as spheroids on ultra-low adherent plates after 7 days. The indicated MYC mutants were constitutively overexpressed exogenously. These results indicate which substitution mutations in MB2 are disruptive of MYC-driven cellular transformation. An unpaired Student's $t$-test was performed to determine standard deviation and statistical significance. $P$-value $\leq 0.05$ was considered statistically significant. Error bars represent SD and ns: $p>0.05,{ }^{*} p \leq 0.05,{ }^{* *} p \leq 0.01,{ }^{* * *} p \leq 0.001,{ }^{* * * *} p \leq 0.0001$. 
(Figure 4B, Supplementary Figure 3). The results show that each of these residues is important for MYC function which correlates with the MYC:TRRAP interaction assay.

\section{DISCUSSION}

Cancer vulnerabilities that can be targeted without harming normal cells have led to major breakthroughs in the development of new treatment options [1]. Studying molecular events that provide cancer cells with proliferative advantages is at the center of these endeavors. The MYC:TRRAP interaction is a MYC vulnerability in cancer and presents an opportunity for drug discovery. Here we show a platform that can be used to identify small molecules as inhibitors of the MYC:TRRAP interaction. Inhibition of MYC and TRRAP binding caused by substitution mutations in MB2 was tested measuring luminescence using a PPI complementation assay, both in cells and in cellular extracts. A decrease in luminescence complementation is indicative of a residue that may participate directly in contacts between MYC and TRRAP. The assay was further corroborated by coIP measurements of the native protein complex and by a MYC-driven cellular transformation assay.

In contrast, achieving MYC inhibition is possible by targeting the DNA-binding domain, but most efforts have met with inescapable off-target toxicity $[10,11]$. However, inhibiting MYC with a compound that binds or targets MB2 and its interaction with TRRAP can be a more fruitful strategy $[5,19]$. The fact that single amino acid substitutions in MB2 were able to abolish the MYC:TRRAP interaction provides convincing evidence that the interaction relies on a sensitive pocket that can be disrupted by small molecules, rather than a large interface like the one found in the MYC:MAX interaction. Inhibition efforts directed at a smaller defined pocket, such as MB2, would likely result in more specific inhibitors. Higher specificity is an advantage over the MYC:MAX inhibitors to date because it allows for precise titrations to achieve lower toxicity. This function identifies an appropriate therapeutic window where only cancer cells are vulnerable to the downregulation of MYC activity. Compounds identified with this platform can lead to a new generation of drugs targeting this unique region of the MYC protein. The uniqueness of MB2 will likely result in very specific therapeutic compounds with minimal offtarget effects, and its essentiality assures that tumor cells cannot escape a treatment strategy that targets MYC's MB2 in cancer. Furthermore, the finding that individual hydrophobic residues within MB2 are essential for the MYC:TRRAP interaction and MYC-driven cellular transformation can be exploited to guide a drug discovery effort. For example, targeted sets of screening compound libraries could be prioritized given that the MYC:TRRAP interaction appears to be driven primarily by hydrophobic interactions. Additionally, our MYC:TRRAP NanoBiT assay could be altered to enhance hydrophobic interactions and raise the potency of the interaction and any potential new inhibitors.

Additionally, it is worth addressing a novel aspect of the biology and importance of the MYC:TRRAP interaction. The structure of Tralp (TRRAP yeast homolog) has been described alone and in complex with part of NuA4 [42, 43]. Tralp is composed of $\alpha$-helical solenoid repeats, spanning both HEAT and FAT domains, which account for $86 \%$ of its mass. For TRRAP, the site of interaction with MYC in the HEAT domain is a predicted intrinsically disordered region (IDR; 2033-2088). Not only does this region contain the two major phosphorylation sites in TRRAP, but it also contains a nuclear localization signal [44-46]. As is the case for DNA-PKcs, it is possible that the IDR, as part of TRRAP's HEAT domain, is involved in an allosteric mechanism of modulation of TRRAP-containing HAT complexes. MYC binding might cause conformational changes to these complexes that regulate their function. The IDR of TRRAP can serve as a 'hot-spot' sensor for cellular events that affect TRRAP and therefore HAT activity.

GCN5 and Tip60 have been reported to acetylate histone tails in vitro but cannot do so for an assembled nucleosome. Both enzymes require other members of the STAGA and NuA4 complexes respectively (TRRAP specifically) for efficient acetylation of assembled nucleosomes [47, 48]. Given these observations and TRRAP's HEAT domain structural similarities with that of DNA-PKcs, TRRAP could be required for efficient HAT activity because it enables the presentation of lysine tails by denaturing nucleosomes. Its HEAT domain could help stabilize relaxed DNA within its large solvent-accessible channels. This model provides a rationale for TRRAP essentiality in MYC cancer biology.

\section{MATERIALS AND METHODS}

\section{Resource availability}

\section{Lead contact}

Further information and requests for resources and reagents should be directed to and will be fulfilled by Michael D. Cole.

\section{Materials availability}

Plasmids and cell lines generated in this study are available upon request unless there is a conflict of interest. This study did not generate any other new unique reagents.

\section{Data and code availability}

This study did not generate any large datasets or analysis code. 


\section{Experimental model and subject details}

HEK293T cell line (ATCC Cat\# CRL-3216, RRID:CVCL_0063): maintained in DMEM (Corning ${ }^{\circledR}$ ) supplemented with $10 \%$ fetal bovine serum (Corning ${ }^{\circledR}$ ), $1 \%$ Penicillin-Streptomycin (Corning ${ }^{\circledR}$ ), and prophylactic Plasmocin $^{\text {TM }}$ (InvivoGen) at $37^{\circ} \mathrm{C}$ with $5 \% \mathrm{CO}_{2}$ and $\geq 80 \%$ relative humidity.

Expi293F cell line $\left(\right.$ Gibco $^{\mathrm{TM}}$ Cat\# A14527, RRID:CVCL_D615): maintained in Expi293 ${ }^{\mathrm{TM}}$ Expression Medium $\left(\mathrm{Gibco}^{\mathrm{TM}}\right)$ at $37^{\circ} \mathrm{C}$ with $8 \% \mathrm{CO}_{2}$ and $\geq 80 \%$ relative humidity and $125 \mathrm{rpm}$ shaking.

MCF-10A cell line (ATCC Cat\# CRL-10317, RRID:CVCL_0598): maintained in DMEM/F12 (Corning ${ }^{\mathbb{R}}$ ) supplemented with $5 \%$ horse serum (Invitrogen), $20 \mathrm{ng} / \mathrm{mL}$ EGF, $0.5 \mu \mathrm{g} / \mathrm{mL}$ Hydrocortisone, $100 \mathrm{ng} / \mathrm{mL}$ Cholera toxin, $10 \mu \mathrm{g} / \mathrm{mL}$ Insulin, $1 \%$ Penicillin-Streptomycin (Corning $\left.{ }^{\circledR}\right)$, and prophylactic Plasmocin ${ }^{\text {TM }}$ (InvivoGen) at $37^{\circ} \mathrm{C}$ with $5 \%$ $\mathrm{CO}_{2}$ and $\geq 80 \%$ relative humidity.

\section{Method details}

\section{Co-transfection}

\section{HEK293T}

HEK293T cells were co-transfected with equal amounts of each plasmid using LipoD293 ${ }^{\text {TM }}$ In Vitro DNA Transfection Reagent per protocol (SignaGen). Cells were plated subconfluently 16-20 hours prior to transfection. After 24 hours, cells were lysed in F-buffer (10 mM TRIS $\mathrm{pH} 7.5,50 \mathrm{mM} \mathrm{NaCl}, 30 \mathrm{mM}$ sodium pyrophosphate, 5 $\mathrm{mM} \mathrm{ZnCl}, 10 \%$ glycerol, $50 \mathrm{mM} \mathrm{NaF}$ ) containing $1 \%$ Triton-X and supplemented with $1 \mathrm{mM}$ PMSF, $10 \mu \mathrm{M}$ Leupeptin, $10 \mu \mathrm{M}$ Pepstatin-A, and $10 \mu \mathrm{g} / \mathrm{mL}$ Aprotinin for co-immunoprecipitations.

\section{Expi293F}

Expi293F cells were co-transfected with adjusted ratios of each plasmid appropriate to the expression of its containing construct using ExpiFectamine ${ }^{\mathrm{TM}} 293$ Transfection Kit per protocol $\left(\mathrm{Gibco}^{\mathrm{TM}}\right)$. New plasmid preparations required optimization of the adjusted DNA ratios. Cells were transfected in flasks in batches of various volumes at $3 \times 10^{6} \mathrm{cells} / \mathrm{mL}$. A bluescript KS+ plasmid (Addgene) was used as carrier DNA when needed, and a pcDNA3.1 EGFP plasmid (ThermoFisher) was used as a fluorescence reporter to determine transfection efficiency. After 48 hours, luminescence measurements were taken or cells were lysed in F-buffer containing 100 $\mu \mathrm{g} / \mathrm{mL}$ Digitonin supplemented with $1 \mathrm{mM}$ PMSF, $10 \mu \mathrm{M}$ Leupeptin, $10 \mu \mathrm{M}$ Pepstatin-A, and $10 \mu \mathrm{g} / \mathrm{mL}$ Aprotinin.

\section{Co-immunoprecipitation}

Immunoprecipitations were performed using anti-PYO (Covance), or anti-MYC (C33 Santa Cruz Biotechnology) agarose pre-conjugated beads at $4^{\circ} \mathrm{C}$ for 16-20 h. Co-immunoprecipitation was analyzed by western blots with the following antibodies: MYC (sc-764 Santa Cruz Biotechnology) or MYC (9402 Cell Signaling Technology), TRRAP (A301-132A Bethel Laboratories), MAX (sc-8011 Santa Cruz Biotechnology), and FLAG (F7425 Millipore Sigma).

\section{Luminescence complementation}

In cells

Transfected Expi293F cells were plated on 96-well white plates with clear bottoms (Greiner). White lightreflecting film (USA Scientific) was used to cover the bottom of the plates for luminescence measurements. Black light-absorbing film was used to cover the top of the plates for fluorescence measurements. All measurements were taken on a SpectraMax i3 instrument (Molecular Devices).

\section{In vitro}

Cells were lysed in the same volume of lysis buffer than that in which they were cultured. Protein concentration of cellular extracts were normalized using a standard BSA protein assay (Bio-Rad Laboratories). After lysis, cellular extracts were plated on 96-well white plates with clear bottoms (Greiner). White lightreflecting film (USA Scientific) was used to cover the bottom of the plates for luminescence measurements. Black light-absorbing film was used to cover the top of the plates for fluorescence measurements. All measurements were taken on a SpectraMax i3 instrument (Molecular Devices).

\section{MCF-10A growth in low attachment assay (GILA)}

MCF-10A cells were engineered with constitutive MYC overexpression or the indicated mutants using a pCDH EF1 $\alpha$-driven lentiviral vector with a puromycin resistance selectable marker. The protocol for GILA measurements was adapted from [41]. Briefly, after selection, $100 \mu \mathrm{L}$ of cells were seeded at $10^{4} \mathrm{cells} / \mathrm{mL}$ in ultra-low attachment 96-well plates from Corning ${ }^{\circledR}$. After a 7-day incubation, cell proliferation was quantified using CellTiter-Glo ${ }^{\circledR} 2.0$ Cell Viability Assay according to manufacturer's instructions. All measurements were taken on a SpectraMax i3 instrument (Molecular Devices).

\section{Quantification and statistical analysis}

All statistical analysis was performed in GraphPad Prism. Measurements were performed in triplicate at least. An unpaired Student's $t$-test was performed to determine standard deviation and statistical significance. $P$-value $\leq$ 0.05 was considered statistically significant. Error bars represent SD and ns: $p>0.05,{ }^{*} p \leq 0.05,{ }^{* *} p \leq 0.01,{ }^{* * *} p \leq$ $0.001,{ }^{* * * *} p \leq 0.0001$. 


\section{Author contributions}

Conceptualization EJF, MDC. Data curation, EJF. Formal Analysis EJF. Funding acquisition EJF, MDC. Investigation EJF, JWH. Methodology EJF, JWH. Project administration, MDC. Resources EJF, MDC. Supervision, MDC. Validation, EJF. Visualization, EJF. Writing - original draft, EJF. Writing - review and editing EJF, JWH, MDC.

\section{ACKNOWLEDGMENTS}

This work was supported by the National Cancer Institute award 5R01CA055248-25 and a Lymphoma Research Foundation Postdoctoral Fellowship award 815436. In addition, we thank the Norris Cotton Cancer Center and the shared resources that are available to its researchers through their funding support from the institutional grant NCI Cancer Center Support Grant 5P30CA023108-40. The sponsors did not play any role in the study design, data collection and analysis, decision to publish, or preparation of the manuscript.

\section{CONFLICTS OF INTEREST}

Two of the authors (EJF, MDC) declare patent holdings in the Patent application 62/942,734 that are related to the subject matter presented in this publication.

\section{REFERENCES}

1. Hanahan D, Weinberg RA. Hallmarks of cancer: the next generation. Cell. 2011; 144:646-74. https://doi. org/10.1016/j.cell.2011.02.013. [PubMed]

2. Bradner JE, Hnisz D, Young RA. Transcriptional Addiction in Cancer. Cell. 2017; 168:629-43. https://doi. org/10.1016/j.cell.2016.12.013. [PubMed]

3. Dang CV, O'Donnell KA, Zeller KI, Nguyen T, Osthus $\mathrm{RC}$, Li F. The c-Myc target gene network. Semin Cancer Biol. 2006; 16:253-64. https://doi.org/10.1016/j. semcancer.2006.07.014. [PubMed]

4. Shachaf CM, Gentles AJ, Elchuri S, Sahoo D, Soen Y, Sharpe O, Perez OD, Chang M, Mitchel D, Robinson WH, Dill D, Nolan GP, Plevritis SK, Felsher DW. Genomic and proteomic analysis reveals a threshold level of MYC required for tumor maintenance. Cancer Res. 2008; 68:5132-42. https://doi.org/10.1158/0008-5472.CAN-076192. [PubMed]

5. Feris EJ, Hinds JW, Cole MD. Formation of a structurallystable conformation by the intrinsically disordered MYC:TRRAP complex. PLoS One. 2019; 14:e0225784. https://doi.org/10.1371/journal.pone.0225784. [PubMed]

6. Jonkers J, Berns A. Oncogene addiction: sometimes a temporary slavery. Cancer Cell. 2004; 6:535-38. https:// doi.org/10.1016/i.ccr.2004.12.002. [PubMed]
7. Kuehl WM, Bergsagel PL. MYC addiction: a potential therapeutic target in MM. Blood. 2012; 120:2351-52. https://doi.org/10.1182/blood-2012-08-445262. [PubMed]

8. Weinstein IB, Joe A. Oncogene addiction. Cancer Res. 2008; 68:3077-80. https://doi.org/10.1158/0008-5472. CAN-07-3293. [PubMed]

9. Carabet LA, Rennie PS, Cherkasov A. Therapeutic Inhibition of Myc in Cancer. Structural Bases and Computer-Aided Drug Discovery Approaches. Int J Mol Sci. 2018; 20:120. https://doi.org/10.3390/ijms20010120. [PubMed]

10. Posternak V, Cole MD. Strategically targeting MYC in cancer. F1000Res. 2016; 5:F1000 Faculty Rev-408. https:// doi.org/10.12688/f1000research.7879.1. [PubMed]

11. Whitfield JR, Beaulieu ME, Soucek L. Strategies to Inhibit Myc and Their Clinical Applicability. Front Cell Dev Biol. 2017; 5:10. https://doi.org/10.3389/fcell.2017.00010. [PubMed]

12. Castell A, Yan Q, Fawkner K, Hydbring P, Zhang F, Verschut V, Franco M, Zakaria SM, Bazzar W, Goodwin J, Zinzalla G, Larsson LG. A selective high affinity MYC-binding compound inhibits MYC:MAX interaction and MYC-dependent tumor cell proliferation. Sci Rep. 2018; 8:10064. https://doi.org/10.1038/s41598-01828107-4. [PubMed]

13. Berg T, Cohen SB, Desharnais J, Sonderegger C, Maslyar DJ, Goldberg J, Boger DL, Vogt PK. Small-molecule antagonists of Myc/Max dimerization inhibit Myc-induced transformation of chicken embryo fibroblasts. Proc Natl Acad Sci U S A. 2002; 99:3830-35. https://doi.org/10.1073/ pnas.062036999. [PubMed]

14. Wang H, Hammoudeh DI, Follis AV, Reese BE, Lazo JS, Metallo SJ, Prochownik EV. Improved low molecular weight Myc-Max inhibitors. Mol Cancer Ther. 2007; 6:2399-408. https://doi.org/10.1158/1535-7163.MCT-070005. [PubMed]

15. Choi SH, Mahankali M, Lee SJ, Hull M, Petrassi HM, Chatterjee AK, Schultz PG, Jones KA, Shen W. Targeted Disruption of Myc-Max Oncoprotein Complex by a Small Molecule. ACS Chem Biol. 2017; 12:2715-19. https://doi. org/10.1021/acschembio.7b00799. [PubMed]

16. Kiessling A, Sperl B, Hollis A, Eick D, Berg T. Selective inhibition of c-Myc/Max dimerization and DNA binding by small molecules. Chem Biol. 2006; 13:745-51. https://doi. org/10.1016/j.chembiol.2006.05.011. [PubMed]

17. Lu X, Vogt PK, Boger DL, Lunec J. Disruption of the MYC transcriptional function by a small-molecule antagonist of MYC/MAX dimerization. Oncol Rep. 2008; 19:825-30. [PubMed]

18. Shi J, Stover JS, Whitby LR, Vogt PK, Boger DL. Small molecule inhibitors of Myc/Max dimerization and Mycinduced cell transformation. Bioorg Med Chem Lett. 2009; 19:6038-41. https://doi.org/10.1016/j.bmcl.2009.09.044. [PubMed]

19. Cowling VH, Cole MD. Mechanism of transcriptional activation by the Myc oncoproteins. Semin Cancer Biol. 2006; 
16:242-52. https://doi.org/10.1016/j.semcancer.2006.08.001. [PubMed]

20. Ichim G, Mola M, Finkbeiner MG, Cros MP, Herceg $\mathrm{Z}$, Hernandez-Vargas $\mathrm{H}$. The histone acetyltransferase component TRRAP is targeted for destruction during the cell cycle. Oncogene. 2014; 33:181-92. https://doi. org/10.1038/onc.2012.570. [PubMed]

21. McMahon SB, Van Buskirk HA, Dugan KA, Copeland TD, Cole MD. The novel ATM-related protein TRRAP is an essential cofactor for the c-Myc and E2F oncoproteins. Cell. 1998; 94:363-74. https://doi.org/10.1016/s0092$\underline{\text { 8674(00)81479-8. }}$ [PubMed]

22. Murr R, Vaissière T, Sawan C, Shukla V, Herceg Z. Orchestration of chromatin-based processes: mind the TRRAP. Oncogene. 2007; 26:5358-72. https://doi. org/10.1038/sj.onc.1210605. [PubMed]

23. Nikiforov MA, Chandriani S, Park J, Kotenko I, Matheos D, Johnsson A, McMahon SB, Cole MD. TRRAP-dependent and TRRAP-independent transcriptional activation by Myc family oncoproteins. Mol Cell Biol. 2002; 22:5054 63. https://doi.org/10.1128/mcb.22.14.5054-5063.2002. [PubMed]

24. Brough DE, Hofmann TJ, Ellwood KB, Townley RA, Cole MD. An essential domain of the c-myc protein interacts with a nuclear factor that is also required for E1A-mediated transformation. Mol Cell Biol. 1995; 15:1536-44. https:// doi.org/10.1128/MCB.15.3.1536. [PubMed]

25. Kalkat M, Resetca D, Lourenco C, Chan PK, Wei Y, Shiah YJ, Vitkin N, Tong Y, Sunnerhagen M, Done SJ, Boutros PC, Raught B, Penn LZ. MYC Protein Interactome Profiling Reveals Functionally Distinct Regions that Cooperate to Drive Tumorigenesis. Mol Cell. 2018; 72:836-48.e7. https://doi.org/10.1016/j.molcel.2018.09.031. [PubMed]

26. Hall MP, Unch J, Binkowski BF, Valley MP, Butler BL, Wood MG, Otto P, Zimmerman K, Vidugiris G, Machleidt T, Robers MB, Benink HA, Eggers CT, et al. Engineered luciferase reporter from a deep sea shrimp utilizing a novel imidazopyrazinone substrate. ACS Chem Biol. 2012; 7:1848-57. https://doi.org/10.1021/cb3002478. [PubMed]

27. Dixon AS, Schwinn MK, Hall MP, Zimmerman K, Otto P, Lubben TH, Butler BL, Binkowski BF, Machleidt T, Kirkland TA, Wood MG, Eggers CT, Encell LP, Wood KV. NanoLuc Complementation Reporter Optimized for Accurate Measurement of Protein Interactions in Cells. ACS Chem Biol. 2016; 11:400-08. https://doi.org/10.1021/ acschembio.5b00753. [PubMed]

28. Desbarats L, Gaubatz S, Eilers M. Discrimination between different E-box-binding proteins at an endogenous target gene of c-myc. Genes Dev. 1996; 10:447-60. https://doi. org $/ 10.1101 / \mathrm{gad} \cdot 10.4 .447$. [PubMed]

29. Huang A, Ho CS, Ponzielli R, Barsyte-Lovejoy D, Bouffet E, Picard D, Hawkins CE, Penn LZ. Identification of a novel c-Myc protein interactor, JPO2, with transforming activity in medulloblastoma cells. Cancer Res. 2005;
65:5607-19. https://doi.org/10.1158/0008-5472.CAN-050500. [PubMed]

30. Cole MD, Henriksson M. 25 years of the c-Myc oncogene. Semin Cancer Biol. 2006; 16:241. https://doi.org/10.1016/j. semcancer.2006.08.003. [PubMed]

31. Albert T, Urlbauer B, Kohlhuber F, Hammersen B, Eick D. Ongoing mutations in the N-terminal domain of c-Myc affect transactivation in Burkitt's lymphoma cell lines. Oncogene. 1994; 9:759-63. [PubMed]

32. Bhatia K, Huppi K, Spangler G, Siwarski D, Iyer R, Magrath I. Point mutations in the c-Myc transactivation domain are common in Burkitt's lymphoma and mouse plasmacytomas. Nat Genet. 1993; 5:56-61. https://doi. org/10.1038/ng0993-56. [PubMed]

33. Bhatia K, Spangler G, Gaidano G, Hamdy N, DallaFavera R, Magrath I. Mutations in the coding region of c-myc occur frequently in acquired immunodeficiency syndrome-associated lymphomas. Blood. 1994; 84:88388. [PubMed]

34. Brennscheidt U, Eick D, Kunzmann R, Martens U, Kiehntopf M, Mertelsmann R, Herrmann F. Burkitt-like mutations in the c-myc gene locus in prolymphocytic leukemia. Leukemia. 1994; 8:897-902. [PubMed]

35. Cerami E, Gao J, Dogrusoz U, Gross BE, Sumer SO, Aksoy BA, Jacobsen A, Byrne CJ, Heuer ML, Larsson E, Antipin Y, Reva B, Goldberg AP, et al. The cBio cancer genomics portal: an open platform for exploring multidimensional cancer genomics data. Cancer Discov. 2012; 2:401-04. https://doi.org/10.1158/2159-8290.CD-12-0095. [PubMed]

36. Cowling VH, Turner SA, Cole MD. Burkitt's lymphomaassociated c-Myc mutations converge on a dramatically altered target gene response and implicate Nol5a/Nop56 in oncogenesis. Oncogene. 2014; 33:3519-27. https://doi. org/10.1038/onc.2013.338. [PubMed]

37. Gao J, Aksoy BA, Dogrusoz U, Dresdner G, Gross B, Sumer SO, Sun Y, Jacobsen A, Sinha R, Larsson E, Cerami E, Sander C, Schultz N. Integrative analysis of complex cancer genomics and clinical profiles using the cBioPortal. Sci Signal. 2013; 6:pl1. https://doi.org/10.1126/ scisignal.2004088. [PubMed]

38. Yano T, Sander CA, Clark HM, Dolezal MV, Jaffe ES, Raffeld M. Clustered mutations in the second exon of the MYC gene in sporadic Burkitt's lymphoma. Oncogene. 1993; 8:2741-48. [PubMed]

39. Chandriani S, Frengen E, Cowling VH, Pendergrass SA, Perou CM, Whitfield ML, Cole MD. A core MYC gene expression signature is prominent in basal-like breast cancer but only partially overlaps the core serum response. PLoS One. 2009; 4:e6693. https://doi.org/10.1371/journal. pone.0006693. [PubMed]

40. Cowling VH, D'Cruz CM, Chodosh LA, Cole MD. c-Myc transforms human mammary epithelial cells through repression of the Wnt inhibitors DKK1 and SFRP1. Mol Cell Biol. 2007; 27:5135-46. https://doi.org/10.1128/ MCB.02282-06. [PubMed] 
41. Izar B, Rotem A. GILA, a Replacement for the Soft-Agar Assay that Permits High-Throughput Drug and Genetic Screens for Cellular Transformation. Curr Protoc Mol Biol. 2016; 116:28.8.1-28.8.12. https://doi.org/10.1002/cpmb.26. [PubMed]

42. Díaz-Santín LM, Lukoyanova N, Aciyan E, Cheung AC. Cryo-EM structure of the SAGA and NuA4 coactivator subunit Tra1 at 3.7 angstrom resolution. Elife. 2017; 6:e28384. https://doi.org/10.7554/eLife.28384. [PubMed]

43. Wang X, Ahmad S, Zhang Z, Côté J, Cai G. Architecture of the Saccharomyces cerevisiae NuA4/TIP60 complex. Nat Commun. 2018; 9:1147. https://doi.org/10.1038/s41467018-03504-5. [PubMed]

44. Daub H, Olsen JV, Bairlein M, Gnad F, Oppermann FS, Körner R, Greff Z, Kéri G, Stemmann O, Mann M. Kinase-selective enrichment enables quantitative phosphoproteomics of the kinome across the cell cycle. Mol Cell. 2008; 31:438-48. https://doi.org/10.1016/j. molcel.2008.07.007. [PubMed]

45. Dephoure N, Zhou C, Villén J, Beausoleil SA, Bakalarski CE, Elledge SJ, Gygi SP. A quantitative atlas of mitotic phosphorylation. Proc Natl Acad Sci U S A. 2008; 105:1076267. https://doi.org/10.1073/pnas.0805139105. [PubMed]
46. Zhou H, Di Palma S, Preisinger C, Peng M, Polat AN, Heck AJ, Mohammed S. Toward a comprehensive characterization of a human cancer cell phosphoproteome. J Proteome Res. 2013; 12:260-71. https://doi.org/10.1021/ pr300630k. [ubMed]

47. Allard S, Utley RT, Savard J, Clarke A, Grant P, Brandl CJ, Pillus L, Workman JL, Côté J. NuA4, an essential transcription adaptor/histone $\mathrm{H} 4$ acetyltransferase complex containing Esa1p and the ATM-related cofactor Tra1p. EMBO J. 1999; 18:5108-19. https://doi.org/10.1093/ emboj/18.18.5108. [PubMed]

48. Grant PA, Duggan L, Côté J, Roberts SM, Brownell JE, Candau R, Ohba R, Owen-Hughes T, Allis CD, Winston F, Berger SL, Workman JL. Yeast Gen5 functions in two multisubunit complexes to acetylate nucleosomal histones: characterization of an Ada complex and the SAGA (Spt/ Ada) complex. Genes Dev. 1997; 11:1640-50. https://doi. org/10.1101/gad.11.13.1640. [PubMed] 